\title{
DAYA ANTIOKSIDAN EKSTRAK KULIT BUAH NAGA DAN SABUN EKSTRAK KULIT BUAH NAGA (Hylocereus polyrhizuz)
}

\section{Antioxidant Activity of Dragon Fruit (Hylocereus polyrhizuz) Peel Extract and Soap of Dragon Fruit Peel Extract}

\section{Mohamad Ikram ' \\ Nining Sugihartini ${ }^{2 *}$}

Any Guntarti ${ }^{3}$

IMahasiswa Pascasarjana Farmasi Universitas Ahmad Dahlan, Yogyakarta, Indonesia

2Fakultas Farmasi Universitas Ahmad Dahlan, Yogyakarta, Indonesia

${ }^{3}$ Fakultas Farmasi Universitas Ahmad Dahlan, Yogyakarta, Indonesia

*email: nining.sugihartini@pharm.uad.ac.id

\begin{abstract}
Abstrak
Ekstrak kulit buah naga merah mengandung betalain yang memiliki aktivitas antioksidan. Selain itu ekstrak juga mengandung zat warna antosian sehingga dapat dipergunakan sebagai zat pewarna pada sediaan kosmetik. Tujuan penelitian ini adalah mengetahui aktivitas antioksidan ekstrak kulit buah naga dan sabun ekstrak kulit buah naga merah dengan berbagai konsentrasi. Aktivitas antioksidan diukur dengan metode DPPH. Konsentrasi ekstrak kulit buah naga merah dalam sabun adalah 0,$3 ; 0,6 ; 0,9 \%$. Hasil uji menunjukkan bahwa sabun ekstrak kulit buah naga merah memiliki aktivitas antioksidan yang lebih rendah dibandingkan ekstraknya. Peningkatan konsentrasi ekstrak menyebabkan peningkatan aktivitas antioksidan sabun ekstrak kulit buah naga merah.
\end{abstract}

\section{Kata Kunci:}

Ekstrak kulit buah naga merah

Sabun

Antioksidan

\section{Keywords:}

Red dragon fruit peel extract

Soap

Antioxidant

\begin{abstract}
Red dragon fruit peel extract contains betalain which has antioxidant activity. In addition, this extract also contains dyes that can be used as coloring agents in cosmetic preparations. The purpose of this study was to study the activity of dragon fruit peel extract and red dragon fruit peel extract soap with various concentrations. Antioxidant activity is taken by the DPPH method. The concentration of red dragon fruit peel extract in soap is $0.3 ; 0.6 ; 0.9 \%$. Test results show red dragon fruit extract soap has lower antioxidant activity than the extract. The increased concentration of the extract caused an increase in the antioxidant activity of the red dragon fruit peel extract soap.
\end{abstract}

\section{PENDAHULUAN}

Kulit buah naga merah memiliki potensi yang besar untuk dapat digunakan sebagai pewarna alami karena terdapatnya kandungan betasianin (Harivaindaran et al., 2008), Efek yang menguntungkan dari betalain adalah mempunyai aktivitas antioksidan (Pavlov et al., 2005; Stintzing et al., 2004). Antioksidan mampu bertindak bertindak sebagai penyumbang radikal hidrogen atau dapat bertindak sebagai akseptor radikal bebas sehingga dapat menunda tahap inisiasi pembentukan radikal bebas. Kulit buah naga memiliki khasiat sebagai antioksidan yang tinggi dibandingkan dengan daging buahnya seperti terdapat kandungan fenolik, flavonoid dan polifenol (Wu et al., 2008). Salah satu sedian kosmetik yang membutuhkan pewarna adalah sabun cair.

Sediaan sabun cair adalah salah-satu sediaan yang membutuhkan penambahan pewarna untuk 
memberikan nilai estetika dan juga merupakan sediaan yang digunakan untuk membersihkan. Sabun dibuat dengan mereaksikan kimia antara kalium atau natrium dengan asam lemak dari minyak nabati atau lemak hewani (Qisti, 2009). Sabun cair juga memiliki bentuk sediaan yang menarik dibandingkan sabun dalam bentuk padatan dan lebih praktis dalam penggunaannya (Sharma et al., 2016). Kelebihan sabun cair dibandingan dengan sabun padat dapat dilihat dari cara proses pembuatannya yang relatif lebih mudah dan biaya produksinya relatif lebih murah dibandingkan dengan proses pembuatan sabun padat (Barel et al., 2009).

Penambahan ekstrak kulit buah naga merah pada formulasi sabun cair, yaitu untuk digunakan sebagai pewrna pada sediaan sabun cair dengan konsentrasi 0.3 g, $0.6 \mathrm{~g}$ dan $0.9 \mathrm{~g}$. Selain digunakan sebagai pewarna untuk sediaan sabun cair, ekstrak kulit buah naga merah juga memiliki aktivitas antioksidan. Dengan konsentrasi yang ditentukan maka formula pada sabun cair ekstrak kulit buah naga merah, memiliki variasi warna yang berbeda. Variasi warna yang berbeda akan memberikan kesan yang menarik, dikarenakan warna pada sedian sabun cair juga bertujuan memberikan nilai estika dalam sediaan. Selain manfaat warna juga akan memberikan manfaat perlindungan terhadap kulit akibat paparan sinar UV atau radikal bebas yang dapat merusak kulit.

\section{METODOLOGI}

\section{Alat dan Bahan}

I. Bahan

Bahan yang digunakan dalam penelitian ini adalah ekstrak buah naga merah, bahan penyusun sabun dengan derajad farmasetis dan larutan DPPH

2. Alat

Alat yang digunakan adalah Spektrofotometer UV Vis $\left(\right.$ Unico ${ }^{\circledR}$ ), kuvet, timbangan digital (Citizen ${ }^{\circledR} M B$ 200).

Jalannya Penelitian

I. Pembuatan ekstrak kulit buah naga merah
Buah naga merah terlebih dahulu dibersihkan kemudian dipisahkan daging buah dan kulit buah naga. Kulit kemudian diblender dan dimaserasi dengan aquadest selama 5 hari. Setelah itu dilakukan freeze drying selama 2 hari.

2. Formulasi sabun cair

Pemilihan formula terpilih berdasarkan hasil orientasi yang dilakukan. Basis yang tampilan visualnya yang stabil, kemudian digunakan sebagai basis dalam formula sabun cair dan ditambahkan ekstrak kulit buah naga merah sebanyak 0,3 g, 0,6g dan $0,9 \mathrm{~g}$. Formula sabun cair disajikan pada table I.

Tabel I. Formulasi sabun cair dengan variasi konsnetrasi ekstrak kulit buah naga merah

\begin{tabular}{cccc}
\hline Bahan baku & $\mathrm{Fl}$ & $\mathrm{F} 2$ & $\mathrm{~F} 3$ \\
\hline Ekstrak Kulit Buah Naga & $0,3 \mathrm{~g}$ & $0,6 \mathrm{~g}$ & $0,9 \mathrm{~g}$ \\
Merah & & & \\
KOH I5\% & $5 \mathrm{ml}$ & $5 \mathrm{ml}$ & $5 \mathrm{ml}$ \\
VCO & $20 \mathrm{ml}$ & $20 \mathrm{ml}$ & $20 \mathrm{ml}$ \\
Asam sitrat 25\% & $10 \mathrm{ml}$ & $10 \mathrm{ml}$ & $20 \mathrm{ml}$ \\
Gliserin & $30 \mathrm{ml}$ & $30 \mathrm{ml}$ & $30 \mathrm{ml}$ \\
SLS & $2 \mathrm{~g}$ & $2 \mathrm{~g}$ & $2 \mathrm{~g}$ \\
Cocamid Dea & $15 \mathrm{ml}$ & $15 \mathrm{ml}$ & $15 \mathrm{ml}$ \\
Aquadest & Ad I00 & Ad I00 & Ad I00 \\
\hline
\end{tabular}

Cara pembuatan sabun cair yaitu mencampurkan VCO dengan Gliserin yang telah dilarutkan dengan $\mathrm{KOH} I 5$ \% lalu diaduk hingga homogen kemudian ditambahkan cocamid dea, diaduk lagi hingga homogen setelah homogen ditambahkan asam sitrat sedikit demi sedikit sambil diaduk homogen lalu ditambahkan SLS setelah basis terbentuk diukur $\mathrm{pH}$ menggunakan kertas $\mathrm{pH}$ untuk memastikan $\mathrm{pH}$ yang diinginkan. Setelah didapatkan $\mathrm{pH}$ yang diinginkan maka dicampurkan dengan ekstrak yang telah dilarutkan dengan aquadest ditambahkan sedikit demi sedikit sambil diaduk homogen hingga terbentuk massa sabun cair.

3. Uji aktivitas antioksidan

Pengujian aktivitas antioksidan dari sampel ekstrak kulit buah naga merah (betalain) yaitu menggunakan metode DPPH (Lee et al., 2003). Ekstrak yang telah diambil sebanyak I $\mathrm{ml}$ divortex selama 30 detik dan ditambahkan DPPH sebanyak $3 \mathrm{ml}$ dan direaksikan selama 30 menit. Setelah bereaksi kemudian dibaca absorbansinya pada panjang gelombang $516 \mathrm{~nm}$. 


\section{HASIL DAN PEMBAHASAN}

Pada penelitia ini digunakan metode maserasi dengan menggunakan pelarut air. Hal ini berdasarkan kelarutan zat aktif di dalamnya yaitu betasianin dan antosianin yang bersifat polar. Betasianin bersifat lebih hidrofilik. Oleh karena itu digunakan pelaut air (Prabowo et al, 2019). Penelitian lain juga menunjukkan bahwa senyawa polar (Vitamin C) dari kulit buah naga merah juga lebih tinggi dalam air dibandingkan dalam pelarut asam sitrat (Ayun dan Reka, 2019).

Ekstrak selanjutnya ditetapkan aktivitas antioksidannya. Penetapan daya antioksidan ekstrak kulit buah naga merah dan sabun disajikan pada tabel II.

Tabel II. Nilai IC 50 ekstrak kulit buah naga merah, sabun dan standar

\begin{tabular}{ll}
\hline Sampel & Rerata \pm SD \\
\hline $\begin{array}{l}\text { Daya antioksidan ekstrak kulit buah } \\
\text { naga }\end{array}$ & $79,8 \mathrm{I} \pm 0,24$ \\
\hline Daya antioksidan sabun FI & $163,19 \pm 0,24$ \\
\hline Daya antioksidan sabun F2 & $127,14 \pm 12,08$ \\
\hline Daya antioksidan sabun F3 & $1 \mathrm{II}, 43 \pm 3,53$ \\
Daya antioksidan standar quersetin & $7,00 \quad \pm 0,16$ \\
\hline
\end{tabular}

Hasil uji menunjukkan bahwa ekstrak kulit buah naga merah memiliki aktivitas antioksidan yang kuat (Molyneux, 2004). Aktivitas antioksidan ini sama dengan hasil penelitian sebelumnya yang menunjukkan bahwa nilai $I C_{50}$ ekstrak kulit buah naga merah yang dimaserasi dengan air pada perbandingan I:50 memiliki nilai antioksidan 5I,35 $\pm 0,87$. Aktivitas tersebut disebabkan kandungan seyawa flavonoid dan fenolik (Manihuruk et al., 2016). Berdasarkan kandungan senyawa tersebut maka digunakan kuersetin sebagai standar yang termasuk golongan flavonoid. Kuersetin sendiri memiliki aktivitas antioksidan yang sangat kuat berdasarkan nilai $I_{50}$ (Molyneux, 2004).

Ekstrak kulit buah naga merah selanjutnya diformulasikan dalam sabun cair. Hasil uji menunjukka bawa setelah difomulasikan dalam sabun maka aktivitas antioksidannya menurun. Aktivitas antioksidan dalam sabun FI masuk kategori lemah sedangkan pada F2 dan
F3 masuk kategori sedang (Molyneux, 2004). Hal tersebut disebabkan kadar ekstrak yang kecil dalam sabun. Selain itu adanya adanya senyawa non polar (VCO) dalam sabun diduga menyebabkan hambatan dalam aktivitas antioksidannya (Purwanto et al., 2019). Peningkatan konsentrasi ekstrak dalam sabun menyebabkan peningkatan aktivitas antioksidan. Hal ini disebabkan karena jumlah zat aktif yang semakin meningkat.

\section{KESIMPULAN}

Formulasi ekstrak kulit buah naga merah dengan konsentrasi $0,9 \%$ dalam sabun cair memberikan aktivitas antioksidan yang sedang. Perlu dilakukan penelitian lanjutan untuk mendapatkan aktivitas antioksidan dalam sabun cair yang lebih tinggi dalam formulasi sabun cair yang tetap stabil baik secara fisik maupun kimia.

\section{UCAPAN TERIMA KASIH}

Peneliti mengucapkan terimakasih atas bantuan semua pihak sehingga terselesaikannya penelitian ini.

\section{REFERENSI}

I. Harivaindaran, K.V., Rebecca, O.P., Chandran, S. 2008. Study of optimal temperature, $\mathrm{pH}$ and stability of dragon fruit ( Hylocereus polyrhizus ) peel for use as potential natural colorant. Pakistan Journal of Biological Sciences. I I: 2259-2263

2. Pavlov, A., Kovatcheva, P., Tuneva, D., llieva, M., Bley, T. 2005. Radical scavenging activity and stability of betalains from Beta vulgaris hairy root culture in simulated condition of human gastrointestinal tract. Plant Foods for Human Nutrition, 60: 43-47

3. Stintzing, F.C., Schieber, A., Carle, R. 2002.vBetacyanins in fruits from red-purple pitaya, Hylocereus polyrhizus (Weber) Britton and Rose. Food Chemistry, 77: I0I-106.

4. Wu, L.C., Hsu, H.W., Chen, Y., Chiu, C.C and Ho, Y.I. 2006. Antioxidantand Antiproliferative Activities ofRed Pitaya, Food ChemistryVolume, 95:319-327.

5. Qisti, R. 2009. Sifat kimia sabun trasnparan dengan penambahan madu pada konsentrasi yang berbeda. Bogor. IPB. 
6. Sharma, A., Yadav, R., Gudha, V, Soni, U.N., Patel, J.R. 2016. Formulation and evaluation of herbal hand wash. World Journal of Pharmcay and Pharmaceutical Sciences, 5 (3):675-683.

7. Barel, A. O., M. Paye, and H.I Maibach. 2009. Handbook of Cosmetic Science and Technology, Third Edition. USA: Informa Healthcare

8. Le Bellec, F., Vaillant, F., and Imbert, E. 2006. Pitahaya (Hylocereus spp.): a new fruit crop, a market with a future. Fruits. 6I (4):237-250

9. Prabowo, I., Utomo, E.P., Nurfaizy, A., Widodo, A., Widjajanto, E., Rahadja, P. 2019. Characteristic and Antioxidant Activities of Anthocyanin Fraction in Red Dragon Fruit (Hylocereus polyrhizuz) Extract. Drug Invention Today. 12(4):670-678

10. Ayun, Q., Eka, R. 2019. Formulasi Sabun Mandi Padat dari Ekstrak Limbah Kulit Buah naga merah ((Hylocereus costaricencis). Biosense. 2(I): 18-27

II. Molyneux, P. 2004. The Use of The Stable Free Radical Diphenylpicrydrazyl (DPPH) for Estimating Antioxidant Activity, Songklanakarin J. Sci. Technol. 26 (2) : I-4.

12. Manihuruk, F.M., Suryati, T., Arief, I.I. 2017. Effectiveness of the Red Dragon Fruit (Hylocereus polyrhizus) Peel Extract as the Colorant, Antioxidant, and Antimicrobial on Beef Sausage. Media Peternakan. 40(I):47-54

13. Purwanto, M., Yulianti, E.S., Nurfauzi, I.N., Winarni. 2019. Karakteristik dan Aktivitas Antioksidan Sabun Padat dengan Penambahan Ekstrak Kulit Buah Naga (Hylocereus polyrizhus). Indonesian Chemistry and Application Journal. 3(I): 14-23 